Long-lived, but not 'aged'

Sir - The growing number of elderly people in society is attracting much interest. Because the matter is of much concern to many people, care must be taken when journals report on ageing matters.

Take, for example, the report of N. Ishii et al. on the oxygen-sensitive mev-1 mutant of the nematode worm (Nature 394, 694-697; 1998). This well-known mutant appears to be defective in mitochondrial electron transport, which could explain its high sensitivity to oxygen poisoning, as shown by its decreased longevity. However, the title of the paper links this result not only to oxidative stress, but also to ageing. Further, the front cover of Nature inaccurately states "Ageing: role of oxidative stress", and the entry on the contents summary page was entitled "Ageing gene". This choice of title is unfortunate.

First, Ishii et al. report longevity, not ageing, data, even though the authors equate a shortening of longevity with premature ageing. Longevity does not provide the same information as ageing data for individuals; many laboratories rightly use biological markers of ageing, such as those provided by the study of behaviour, rather than relying solely on longevity data. Longevity is a measure of duration, not of content. We all know people of the same longevity, say 90 years old, who were bedridden or who were able to go jogging — knowing the longevity of individuals is not the same as knowing their physiological status or quality of life.

Second, Nature's title "Ageing gene" gives the impression that there could be genes governing the way we age. It is wellknown that many genes may have effects on various features of the ageing process, but it is not correct to suggest that mendelian genes determine the ageing process. It is well-recognized by gerontologists that genes decreasing longevity are not strong arguments for a genetic determinism of longevity. Many mutants, due to their negative defects, have a low longevity, and attempts to find mutants where lifespan is increased have failed except in nematodes. Human genetic diseases often decrease lifespan, but it is generally accepted that their study is of little help in understanding normal ageing.

Our purpose is not to criticize the interesting work of Ishii et al. But we do wish to draw attention to the need to use the word 'ageing' with care when reporting on longevity, and we do wish to ask authors and journals to avoid titles that may misrepresent gerontological research. Eric Le Bourg Nadège Minois

Laboratory of Ethology and Animal Psychology, UMR CNRS No. 5550,

Université Paul Sabatier,

118 route de Narbonne,

F-31062 Toulouse cedex 4, France

e-mail: lebourg@cict.fr

\section{What's in a name}

\section{(or a number or a date)?}

Sir - A great deal of faith is placed in impact factors and citation analyses of published work, not least by institutions being assessed for research quality. These measures assume that the primary data on referenced work are of high quality. But this assumption can be far from the truth.

Take a well-known paper by Marion M. Bradford, entitled "A rapid and sensitive method for the quantitation of microgram quantities of protein utilizing the principle of protein-dye binding" (Analytical Biochemistry 72, $248-254 ; 1976)$. This highly cited paper (well over 10,000 citations) describes a very convenient method for the determination of the amount of protein with reference to a protein standard. It has a single author, and is the only paper published by her in this journal during the 1970s.

Inspection of the BIDS/ISI database reveals that, even when the name of the author and the year are correctly specified, the article has been referred to in 156 different ways, 153 of them giving an incorrect volume number or journal title. In a second search, the date of the article was incorrect in 63 ways. In a third search for which the correct year was specified, the second initial of the author has been omitted (75 errors) or given incorrectly
( 15 errors). So there are more than 300 ways in which this article has been referred to incorrectly in published work, amounting to more than 2,000 individual citations.

Apart from raising doubts about the validity of citation exercises, errors in the details of referenced work make it timeconsuming for the reader to track down the correct article, and do authors a major disservice by underestimating the impact of their work.

This is by no means an isolated example. Similar exercises on other highly cited papers that describe commonly used biochemical procedures, such as those of Lowry et al. (J. Biol. Chem. 193, 265-275; 1951) or Laemmli (Nature 227, 680-685; 1970), show that each of these papers has been referred to in at least 200 incorrect ways.

Who is responsible for checking the accuracy of references in published work? The primary responsibility must lie with authors submitting work for publication. The reviewing and editing process does not seem to be effective in preventing mistakes appearing in the published literature. Should the publishers and the compilers of databases have any responsibility in checking the accuracy of the information? Whatever the answer to this question, it is clear that quality-control procedures are not working satisfactorily.

\section{Nicholas C. Price}

Department of Biological Sciences,

University of Stirling, Stirling FK9 4LA, UK e-mail:ncp1@stirling.ac.uk

\section{Each to his own}

Sir - It is perfectly fine to poll leading scientists about God ${ }^{1}$, but scientists are elected to the US National Academy of Sciences because they are great in one area. This election does not imply "superior knowledge"2 in other subjects, especially one so personal as a belief in God. One British scientist is quoted ${ }^{1}$ as writing: "But I don't think you can be a real scientist in the deepest sense of the word" and "have religious beliefs". This is condescension, not insight.

There is a saying in theology that "For those who believe, no proof is necessary. For those who do not believe, no proof is possible". Some religions claim that divination of religious truths, including faith, represents insights bestowed on a person (rather than earned through some 'deep' probing). Great scientists are often fascinating persons. If as a whole they do not believe in God, so be it. But let us not extrapolate the implications of such a census to something about deeper universal truths. (The authors of ref. 1 make no attempt to draw such an inference; they merely report the results.)

Thomas J. Crowley

Department of Oceanography,

Texas AઐM University, College Station,

Texas 77843-3146, USA

e-mail:tcrowley@ocean.tamu.edu

1. Larson, E. J. \& Witham, L. Nature 394, 313 (1998).

2. Leuba, J. H. The Belief in God and Immortality: A Psychological Anthropological, and Statistical Study (Sherman, French \& Co, Boston, 1916). 